\title{
Human Factors Experiences in Context - Comparing Four Industrial Cases Using a Soft Systems Framework
}

\author{
Cecilia Berlin*
}

\author{
Chalmers University of Technology, Department of Product and Production Development, Division of Production \\ Systems, Hörsalsvägen 7A, 41296 Gothenburg, Sweden
}

\begin{abstract}
In industrial production companies, the practice of assigning responsibility for human factors and ergonomics (HFE) to specific professionals (referred to as HF agents in this paper) may take on various organizational forms. This interview study examines the extent to which HF agents are able to give input towards the design of new production systems in different industrial sectors. The present paper reports on how HF agents work in four Canadian case companies from the Automotive, Nuclear Power, Poultry and Auto parts sectors. A stratified soft-systems framework was used to guide the comparison of the four case companies regarding the HF agents' positioning in their companies and how this influences their work practices. HF agents and a cluster of $2-3$ surrounding colleagues with adjacent responsibilities were interviewed.

Results showed that company context-specific factors such as procedures, collegial relations, processes and culture all heavily influence the "infrastructure" the HF agents can make use of to advance and sustain a human factors/ergonomics agenda. This includes vertical support in the company hierarchy (management support from top-down, employee acceptance from bottom-up), available tools and methods for demonstrating HFE benefits, and proceduralized accountability for HFE in projects. The companies that report positively on being able to address HFE issues proactively have HFE input integrated procedurally into new project start-ups, and the HF agent has a sign-off role. These companies have also, on a high organizational level, established linkage between HFE improvements and business objectives.
\end{abstract}

Keywords: Organizational ergonomics, qualitative study, comparison study, macroergonomics, soft systems, empirical study.

\section{INTRODUCTION}

In industrial production companies, the practice of assigning responsibility for human factors and ergonomics (HFE) to specific professionals (referred to as HF agents in this paper) may take on a variety of organizational forms. The present paper reports on a study of HF agents' work in four Canadian case companies, based on semi-structured interviews. The objective of the study was to develop theory about how HFE is advanced in different industrial sectors and to examine how existing collaboration procedures could influence reactive and proactive HFE work. This study operates from a non-intervening, practice-oriented point of view, focusing on four contemporary companies' ongoing, day-to-day HFE activities and procedures.

\subsection{Socio-Technical Perspectives on HFE Work}

The processes that surround HFE work are not only technical in nature, but also social, relational and heavily influenced by context and environment. On several levels, the HF agents' priorities, actions and ability to influence HFE issues are influenced by company-specific values, organizational solutions and cultures. Comparing their practices can be a daunting task, but previous literature provides some helpful structure. This study adopts a view of

*Address correspondence to this author at the Chalmers University of Technology, Department of Product and Production Development, Division of Production Systems, Hörsalsvägen 7A, 41296 Gothenburg, Sweden; Tel: +46-31-772 1290; E-mail: cecilia.berlin@chalmers.se soft systems thinking, which recognizes that different people may or may not perceive a particular situation as problematic, and in exploring the situation, the inquiring process itself can be structured as a system of learning [1].

The influence of organizational, social and sociotechnical factors on HFE work has been examined and emphasized as important in several previous works (e.g. [2, 3]). No HFE improvements can be made independently of a social corporate setting; therefore it is important to consider interactions with other 'surrounding' stakeholders (with adjacent domains of responsibility) as part of the working reality of the HF agents, something that has been proposed in e.g. $[4,5]$.

Hendrick [6] warned that systematic failure to consider an organization's key socio-technical characteristics is the reason why technology-centered HF approaches often fail to meet their goals. Theberge and Neumann [4] wrote that ergonomics work is of a relational nature, and that practitioners must engage in "organizational work" and be politically aware in their recommendations to achieve ergonomics changes. A case study [7] warned that physical separation between operators and engineers reduces the chance of system user feedback reaching engineers, resulting in disassociation between system design and system alterations done on-site. According to [7], getting ergonomics strategies into design processes is heavily reliant on the existence of and compliance with specifications, codes and standards. Kirwan [8] stated that HFE implementation is determined by the inter-relationships between HF personnel and those who control existing procedures. Another conclusion of Kirwan's was that system design is likely to depend on an 
ergonomist's credibility within a department and how well conclusions are related to company goals and performance criteria ([8], p. 664). All these findings motivate further research regarding how HFE advancement is influenced by the perspectives of the HFE practitioners' colleagues, and the linkages of HFE to company goals.

\subsection{Aims}

The aim of the present research is to gain a deeper understanding of the ways in which industrial company context, collaborations and processes can influence HFE practices, and to examine the perspectives of not only HFE practitioners but also their surrounding colleagues. A wider goal is to contribute to the contemporary "picture of the state of the art" [9] and examine the way that HFE is addressed in four contemporary industrial companies in different sectors.

\section{METHODOLOGY}

\subsection{Data Collection}

The study was conducted under the supervision of the Human Factors Engineering Lab at Ryerson University, and was cleared in advance by Ryerson University's Research Ethics Board.

Companies from different industries were approached through personal contact with their HF agent. Recruitment was initiated from within Canada, using contact networks such as the Association of Canadian Ergonomists, personal networks, and approaches to individual production companies by calling their switchboard and inquiring for personnel responsible for Human Factors/Ergonomics. Contact was initiated through an e-mailed written description of the study's objectives and setup, followed up by email or telephone contact to inquire about the HF agent's interest in participating. Participating companies were selected on the basis of 1) the HF agent's availability and consent to participate, and 2) being able to provide contact with at least two additional staff members working with adjacent domains of responsibility to the HF agent's. Some companies declined, due to inconvenience or lack of time. The result was that four companies from the automotive, auto parts, fresh food and nuclear power sectors fulfilled the criteria and were recruited.

All four companies had factories in Canada and/or North America, and the majority of participants worked in Canada. Prior to each interview, participants were sent a written description of the study procedure and how recorded material would be handled. Informed participation consent was given orally by each participant (and audio recorded) at the start of each interview.

The data collection consisted of individual interviews at four industrial companies. At the centre of each interview 'cluster' was a practitioner whose domain of responsibility fit the $H F$ Agent description mentioned earlier. Via the interview with the HF agent, 'snowball recruitment' of an additional $2-3$ colleagues identified as significant collaborators with influence on HFE work was initiated, to gain the input of surrounding stakeholders interacting with the HF agent. Recruitment was subject to availability and convenience, but in all four companies, colleagues from higher-level management and engineering were represented.
Interviews were semi-structured and lasted between 30 minutes to one hour. All interviews were conducted by the article author by phone or in person. Each participant was interviewed about their work practices, objectives, tools and procedures they used, involvement with design of new systems, how activities related to HFE issues, and interactions with their closest colleagues. The script is available from the corresponding author on request. The interviews were audio recorded and fully transcribed verbatim.

\subsection{Sample}

A total of 14 participants took part in the study. The automotive (Company A) and nuclear (Company B) clusters consisted of three participants, while the poultry (Company C) and auto parts (Company D) clusters included four participants. In the two latter cases, this was due to the 'snowball' recruitment of two HF agent representatives within the same organization - one locally oriented towards a specific site, and one with a more centralized position at a 'Mother Corporation' (MC). Table 1 presents each of the interviewees in brief.

Company A manufactures automobiles, producing several different models simultaneously in factories across North America using line-based production. Company B produces nuclear power, generating a substantial percentage of Canada's power grid. The studied local plant of Company $B$ runs and maintains two reactors, and the majority of system change activities are focused on safe operation and maintenance of the reactors. Company $\mathrm{C}$ produces various food products. The study focuses mainly on a local poultry plant since three cluster interviewees worked at the same one, while the perspective of $\mathrm{C} 1$ (Manager of ergonomics) provided information about the company-wide, large-scale approach to ergonomics. Company D produces truck frames and is one of several producers specializing in a specific type of auto parts, which are all organized under a Mother Company (MC), which operates as a plant 'branch' in its own right.

\subsection{Coding}

Coding of the transcripts was facilitated by entering the data into a qualitative data management tool [10]. The coding schemes emerged through iterative reading of the verbatim interviews, identification of categories as recurring or contrasting themes emerged, and discussions between the author and experienced colleagues as the coding work progressed. The categorizing process led to a set of key concepts that appeared across several of the companies. The exact codes that emerged can be made available on request from the corresponding author.

\section{RESULTS AND ANALYSIS}

Each of the studied companies centered on a specific type of production or manufacturing process, and the HFE activities they reported were often specific to the particular type of product, production and organizational culture at each particular company. For the sake of brevity, most accounts are presented here in summarized form, but all statements are based on verbatim quotes from the interviews. 
Table 1. Interviewees at Companies $A, B, C$ and D, Starting with the HF Agent

\begin{tabular}{|c|c|c|}
\hline Interviewee & Position & Comment \\
\hline A1 & $\begin{array}{l}\text { Company production } \\
\text { ergonomist }\end{array}$ & $\begin{array}{l}\text { - Female, age 30,6 years in current position. } \\
\text { - Bachelor of Human Kinetics, Master of Engineering Management, Certified Kinesiologist, candidate for } \\
\text { Certified Professional Ergonomist } \\
\text { - Works with day-to-day and future plant production issues. } \\
\text { - Has an industrial engineering background. }\end{array}$ \\
\hline $\mathrm{A} 2$ & Chief Engineer & $\begin{array}{l}\text { - Male, age 37, } 0.5 \text { years in current position. } \\
\text { - Bachelor of Mechanical Engineering, Master of Engineering Management } \\
\text { - Is responsible for three vehicle models. }\end{array}$ \\
\hline A3 & Mid-level manager & $\begin{array}{l}\text { - Male, age } 49,4 \text { years in current position. } \\
\text { - Bachelor of Chemical Engineering, Master of Business Administration, Automotive Training } \\
\text { - Responsible for making sure that components of the vehicle are able to physically co-exist, by means of } \\
\text { mostly virtual (and some physical) 3D simulation. }\end{array}$ \\
\hline B1 & $\begin{array}{l}\text { Human Factors Resource } \\
\text { Person }\end{array}$ & $\begin{array}{l}\text { - Male, age 41, } 2 \text { years in current position. } \\
\text { - Bachelor of Kinesiology/Biology, Master of Psychology/Human Factors, Certified Ergonomics } \\
\text { Associate } \\
\text { - Organizationally located under Engineering. Works under B2. } \\
\text { - Mainly concerned with evaluating and signing off on engineering changes. }\end{array}$ \\
\hline B2 & $\begin{array}{l}\text { Manager of Mechanical } \\
\text { Projects }\end{array}$ & $\begin{array}{l}\text { - Female, age } 37,1 \text { year in current position. } \\
\text { - Bachelor of Industrial Systems Engineering, Master of Psychology, Professional Engineer (P.Eng) } \\
\text { - Organizationally located under Engineering and manages B1. } \\
\text { - Formerly in the Human Factors specialist position now held by B1. }\end{array}$ \\
\hline B3 & Senior Technical Engineer & $\begin{array}{l}\text { - Male, age 36, } 3 \text { years in current position. } \\
\text { - Bachelor of Engineering Technology, Mechanical Engineering Technologist } \\
\text { - Organizationally located at the Instrumentation and Controls department. }\end{array}$ \\
\hline $\mathrm{C} 1$ & $\begin{array}{l}\text { Manager of Ergonomics } \\
\text { at Company C (global) }\end{array}$ & $\begin{array}{l}\text { - Female, age 50, } 20 \text { years in current position. } \\
\text { - Degree in Nursing and Bachelor of Kinesiology/Ergonomics, Canadian Certified professional } \\
\text { Ergonomist, Registered Practical Nurse } \\
\text { - Works with researching, suggesting and implementing technical solution changes in Company C's } \\
\text { various production plants. }\end{array}$ \\
\hline $\mathrm{C} 2$ & $\begin{array}{l}\text { Plant manager at local } \\
\text { poultry plant }\end{array}$ & $\begin{array}{l}\text { - Male, age } 51,20 \text { months in current position. } \\
\text { - Bachelor of Technology } \\
\text { - Manages C } 3 \text { and } \mathrm{C} 4 \text {. } \\
\text { - Runs the plant in compliance with safety and output standards. }\end{array}$ \\
\hline $\mathrm{C} 3$ & $\begin{array}{l}\text { Project engineer at poultry } \\
\text { plant }\end{array}$ & $\begin{array}{l}\text { - Male, age } 29,1.5 \text { years in current position. } \\
\text { - Bachelor of Mechanical Engineering } \\
\text { - Coordinates a number of engineering projects and implementations of new products. }\end{array}$ \\
\hline $\mathrm{C} 4$ & $\begin{array}{l}\text { Manager of Health, Safety, } \\
\text { Security and Environment } \\
\text { (HSSE) at poultry plant }\end{array}$ & $\begin{array}{l}\text { - Female, age 27, } 3 \text { weeks in current position. } \\
\text { - Bachelor of Arts, Certified Ergonomic Specialist, First Aid, Certified Kinesiologist } \\
\text { - Relatively new work position, was formerly the plant ergonomist for } 3.5 \text { years. } \\
\text { - Organizationally positioned with Health and Safety department. }\end{array}$ \\
\hline D1 & $\begin{array}{l}\text { Manager of Global } \\
\text { Ergonomics, mother } \\
\text { company (MC) }\end{array}$ & $\begin{array}{l}\text { - Male, age } 34,4 \text { years in current position. } \\
\text { - Master of Science, Certified Professional Ergonomist } \\
\text { - Works with training ergonomics committees at plants and monitoring ergonomics performance at all } \\
\text { plants. }\end{array}$ \\
\hline D2 & Ergonomist (plant) & $\begin{array}{l}\text { - Male, age } 29,5 \text { years in current position. } \\
\text { - Bachelor of Ergonomics/Psychology, Associate Ergonomist } \\
\text { - Organized under Human Resources. } \\
\text { - Mainly concerned with proactive (design-related) ergonomics and new projects. }\end{array}$ \\
\hline D3 & $\begin{array}{l}\text { Department Manager of } \\
\text { Engineering and Quality } \\
\text { (plant) }\end{array}$ & $\begin{array}{l}\text { - Male, age } 40,2 \text { years in current position. } \\
\text { - College diploma, Certificate of qualification in Tool and Die } \\
\text { - Tracks projects within the Engineering and Quality departments against time lines and budgets. } \\
\text { - Coordinates business between production and external customers. }\end{array}$ \\
\hline D4 & $\begin{array}{l}\text { Process Engineering } \\
\text { Coordinator (plant) }\end{array}$ & $\begin{array}{l}\text { - Male, age 32,6 years in current position. } \\
\text { - Manufacturing Engineering Technology Diploma } \\
\text { - Designs and builds new systems in collaboration with equipment manufacturers. } \\
\text { - Quotes new business in a cross-functional team including several stakeholders. }\end{array}$ \\
\hline
\end{tabular}


A conceptual framework [8] (pp. 666-678) is used to report the results in a structured, stratified manner Appendix A provides a more detailed explanation of the framework. Each reporting section starts with a comparison of characteristics relevant to that level across companies (Tables 2-6). Starting with working conditions close to the HF agent and gradually expanding outwards through organizational-structural levels toward the organization's environment, the framework compares different aspects of the four case companies. It should, however, be remembered that Kirwan's framework was not used to devise the conceptual structure of the interview guide, and therefore some levels are condensed and reported together.

\subsection{Where the HFE Work Happens}

The "Technical interface" level of Kirwan's [8] framework describes where, how, and in what form interactions between stakeholders take place, e.g. in the form of meetings, reports and various means of communication. Table 2 shows a comparison of key characteristics displayed by the four companies in this regard.

\section{Company A - A Digital Meeting Workflow}

Company A has sophisticated technology and multiple resources for visualizing and documenting HFE knowledge. For new projects, Company A has implemented a system of Digital Reviews, meetings where cross-disciplinary product "launch" teams regularly meet to discuss different aspects of a vehicle model, in digital 3D representation. As part of the launch team, A1 (the ergonomist) looks at all prototype parts and evaluates them according to a HF checklist built on documented previous project experience. If any checklist points are exceeded, a "red flag" (a warning that something might become a future problem) is generated. A1 then performs a secondary analysis, and if necessary will lead a design change process involving the responsible engineer and other affected stakeholders (such as production or quality). According to A1, communication is on an informal and as-needed basis, and happens in person, via phone or via email. Ergonomists remain assigned to new products for two months after they have been launched in the plant, in order to catch any missed issues. A1 mentions that Company A also has a set of product guidelines aimed at suppliers.
On a higher organizational level, A2 (the chief engineer) attends weekly product management team meetings where different engineering representatives report on the status of their area's projects. A specific department at Company A builds human 3D-simulation models, and A3 (mid-level manager) reports the use of "knowledge-based engineering templates" which mathematically link parameters in 3D models and give alerts if any modelled changes exceed guidelines.

\section{Company B - HF Sign-Off on All Changes}

Company B uses an electronic process protocol for tracking engineering changes, and has several technological resources for gaining and documenting operational experience - B1 (the human factors specialist) reports that the process protocol helps to involve HF in projects in a timely manner. There are extensively documented guidelines for design support and procedural compliance. Software for various work tasks is available, although Company B participants reported differently about how easy they are to get access to. Additionally, the participants have access to a head-office simulation/calculation support group who help out with calculations and modelling of different design parameter aspects.

B2 (manager of mechanical projects) reports holding one weekly meeting with the entire department, and bi-weekly meetings with people working immediately under her. B1 and a student intern continually update B2 on the status of projects and raise any HFE issues needing attention.

According to B3 (a senior technical engineer), the change process protocol requires engineers to contact $\mathrm{B} 1$ for input. If B1 finds the detail or conceptual designs satisfactory he signs off, adds notes to the process protocol forms and fills out risk rankings, or if needed, asks for continual involvement as a stakeholder. B1 has given input to 3Dmodels of the workplace, but has not actively used the software. B2 reports that the company has a screening process to ensure that construction, operation and maintenance aspects are considered in change projects. This screening process includes a section on HF and physical ergonomics in checklist format. Any issues that are identified by the checklist raise "red flags" to get the HFE personnel involved.

Table 2. Key Characteristics of Companies A, B, C and D at the Technical Interface Level

\begin{tabular}{|c|c|c|c|c|}
\hline Level & Company A - Automotive & Company B - Nuclear & Company C - Poultry & Company D - Auto Parts \\
\hline Technical Interface Level & $\begin{array}{l}\text { - Digital workflow using } \\
\text { 3D product models } \\
\text { - Regular cross- } \\
\text { disciplinary team digital } \\
\text { review meetings } \\
\text { - Ergonomist assigned to } \\
\text { product team } \\
\text { - HFE checklist points - } \\
\text { discussed if limits are } \\
\text { exceeded } \\
\text { - Supplier guidelines } \\
\text { - Templates for simulation } \\
\text { engineers including HF } \\
\text { checklists }\end{array}$ & $\begin{array}{l}\text { - Electronic process for } \\
\text { tracking engineering } \\
\text { changes } \\
\text { - HF specialist has sign-off } \\
\text { role on change issues } \\
\text { - Extensive documentation } \\
\text { \& guidelines } \\
\text { - Small HF unit of } 3 \\
\text { people } \\
\text { - Continuous } \\
\text { documentation } \\
\text { - Screening procedure with } \\
\text { HF checklists }\end{array}$ & $\begin{array}{l}\text { - HFE work not embedded } \\
\text { in engineering processes } \\
\text { - Use of mainly } \\
\text { flowcharts, 3D layout } \\
\text { software, employee } \\
\text { surveys } \\
\text { - Video and photos } \\
\text { invaluable for HF } \\
\text { communication } \\
\text { - Informal communication } \\
\text { processes at local plant } \\
\text { - Rapid changes to } \\
\text { production }\end{array}$ & $\begin{array}{l}\text { - Electronic reporting } \\
\text { system for plant } \\
\text { scorecard metrics } \\
\text { - HFE support and training } \\
\text { available to all plants } \\
\text { through central HF } \\
\text { agents (MC) } \\
\text { - Site-specific ergonomists } \\
\text { at local plant } \\
\text { - Great autonomy in how } \\
\text { HFE issues are addressed } \\
\text { locally }\end{array}$ \\
\hline
\end{tabular}




\section{Company C-Globally Proactive, Locally Reactive}

In Company $\mathrm{C}$, HFE work is not as embedded into technological processes as in the previous two companies. The product and production processes for poultry do not lend themselves to being modeled or simulated - for this reason, the technological aids for HFE work at Company $\mathrm{C}$ are mainly in the form of visualization tools such as flowchart or 3D layout software, digital imaging, and physical charts on walls. $\mathrm{C} 1$ (the global ergonomics manager) and $\mathrm{C} 4$ (the HSSE manager, formerly the ergonomics coordinator; see Table 1) chiefly use employee discomfort surveys and digital cameras as data collection tools. C1 considers video and images to be an invaluable tool for demonstration purposes at meetings. She briefly tried using human simulation software for a time, but was dissatisfied with the slowness of using the program compared to her own knowledge of ergonomics and equipment.

Communication processes are mostly informal in Company $\mathrm{C}$, although the studied plant holds weekly meetings. $\mathrm{C} 1$ sometimes travels between plants and presents new layouts or solution proposals for equipment at weekly meetings. The plant also has monthly meetings for the higher-level stakeholders to report on issues. According to $\mathrm{C} 4$, there is a strict order in which the sections report: first Human Resources reports on staffing, then Health and Safety discusses the plant's medical status, then Food Safety informs about e.g. customer complaints, and lastly Finance gives a report. $\mathrm{C} 4$ says that meetings are the only real way of being informed of changes to the plant floor: "What tends to happen is, I find it once it's already well on its way to be implemented, or implemented, or already at the plant. (...) sometimes I usually just find out in the meetings that, 'oh, this has been installed this weekend'. (...) maybe now I'll see more what's coming. But as a coordinator before, absolutely nothing."

C1 also reports that the company's Senior Vice President suggested sending out a quarterly ergonomics newsletter to all plant managers to increase the company awareness of successful HFE plant modifications.

\section{Company D - Global and Local HFE Guidance}

The technological support resources for HFE at Company $\mathrm{D}$ are diverse. On a global level, all plants are able to request ergonomics training, expertise and ergonomics simulation aid from the Mother Company (MC). Some plants follow the rolled-out ergonomics committee program supplied by $\mathrm{MC}$, while others have in-house plant ergonomists who provide HFE support locally (which is the case in Company D). D2 (the plant ergonomist) reports having access to a variety of modeling software and analysis tools. Other embedded HFE process aids include an electronic reporting system for plant scorecard metrics (including ergonomics), an engineering product development process, Safety checklists, bestpractices guidelines and engineering analysis tools like the " $E-F M E A$ ", described by D4 (the process engineering coordinator) as a modified Failure Mode and Effects Analysis with an ergonomics profile - it evaluates risks and generates a red, yellow or green "score".

D1(manager of global ergonomics at MC) reports that some years ago, when ergonomists tried to approach ergonomics issues through Human Resources or Health and
Safety, the issues would be sent to the Engineering function who had no accountability for ergonomics; thus HFE changes were not organizationally supported. However, each plant is now monitored quarterly with scores on a set of criteria, among which ergonomics is one alongside approximately 25 other top plant-managerial concerns. Also, D3 (the engineering and quality manager) reports that there are post-project meetings where "lessons learned" are discussed and brought into future projects.

\subsection{Who Does What, and How}

At the Project, Company and Personnel levels (Table 3) described by Kirwan [8], the typical nature of HF projects or assignments, the organizational positioning of the HF agents and what other organizational functions they interface with, and how the 'ranking level' of HF agents affects their practices and level of influence are described respectively. These characteristics are strongly intertwined; therefore, they are reported together for reasons of brevity.

\section{Company A - Large-Scale Product Launches Every Six Years}

A1 frequently gets assigned to more than one plant at the same time, meaning that she gives HFE input to both reactive and proactive projects across various sites in both the US and Canada. A2 notes that since most of the ergonomics personnel handle several parallel projects, they sometimes get spread too thin and some HFE issues are missed.

A1 belongs to a group of eight ergonomists - which A1 describes as a "free-floating function" in the organization who are assigned to new programs distributed on a vehicleplatform basis. They report to a manager responsible for ergonomics and industrial engineering. Bigger model projects, "launches", happen approximately every six years and each project is assigned a launch team, a crossfunctional group consisting of representatives from a variety of departments including "safety, ergonomics, industrial engineering, vehicle development, plant engineering, facilities engineering, material handling (...) someone from production, like a supervisor or an area manager" (A1). The launch team meets regularly to ventilate concerns about the project's different aspects. A1 reported working especially closely with the company's Safety function, since ergonomics issues were often also considered to "go hand in hand" with safety issues. A1 reported very good support for HFE from upper-level management, and that company-wide commitment to involving ergonomics had increased rapidly during the last five years before the interview. Still, A1 says, some resistance remains in the company in the form of "oldschool engineers" who were not trained in ergonomics as part of their education and find it a "bogus science". A1 notes that many sceptical engineers have been won over by having the benefits of early ergonomics involvement expressed in terms of cost savings.

\section{Company B - Constantly Ongoing Workplace Changes}

B1 organizationally belongs to the Engineering department, has an immediate superior with a HF background (B2) and a student intern as an additional resource. This small but collected HFE unit provides a stable 'sounding off' group who quickly inform each other of 
Table 3. Key Characteristics of Companies A, B, C and D at the Project, Company and Personnel Levels

\begin{tabular}{|c|c|c|c|c|}
\hline Level & Company A - Automotive & Company B - Nuclear & Company C - Poultry & Company D - Auto Parts \\
\hline Project level & $\begin{array}{l}\text { - Major model releases, } \\
\text { "launches", every six } \\
\text { years } \\
\text { - Work in cross-functional } \\
\text { groups }\end{array}$ & $\begin{array}{l}\text { - Most HFE-related } \\
\text { assignments concern } \\
\text { replacement of parts } \\
\text { - Small, effective HFE unit } \\
\text { of three HF agents } \\
\text { - HF resource is able to } \\
\text { prioritize involvement } \\
\text { - Many interlocking } \\
\text { procedures make large- } \\
\text { scale changes difficult to } \\
\text { implement }\end{array}$ & $\begin{array}{l}\text { - Short implementation } \\
\text { times for new } \\
\text { products(weeks to } \\
\text { months) } \\
\text { LOCALLY: } \\
\text { - Local HF agent not } \\
\text { always involved until } \\
\text { after implementation } \\
\text { - HFE issues mostly } \\
\text { addressed as retrofitting } \\
\text { GLOBALLY: } \\
\text { - C1 works with "seeing } \\
\text { opportunities" relating } \\
\text { HFE to business, } \\
\text { productivity etc. }\end{array}$ & $\begin{array}{l}\text { - Order-based production, } \\
\text { typically } 24 \text { months from } \\
\text { request to production } \\
\text { launch } \\
\text { LOCALLY: } \\
\text { - HFE organized under } \\
\text { Human Resources } \\
\text { (locally at Company D) } \\
\text { - Ergonomists collaborate } \\
\text { closely with medical staff } \\
\text { - Ergonomist (D2) has a } \\
\text { sign-off role from the } \\
\text { design stage } \\
\text { GLOBALLY: } \\
\text { - Corporate ergonomists } \\
\text { roll out training and } \\
\text { support programs } \\
\text { - Ergonomics status } \\
\text { tracked in each company } \\
\text { using a scorecard metric }\end{array}$ \\
\hline Company Level & $\begin{array}{l}\text { Ergonomists are "free- } \\
\text { floating" function, } \\
\text { assigned to multiple } \\
\text { plants and projects } \\
\text { - Close collaboration of } \\
\text { HF agent with company } \\
\text { Safety function }\end{array}$ & $\begin{array}{l}\text { - HFE belongs to } \\
\text { Engineering department } \\
\text { - Compliance with HFE } \\
\text { mandated through } \\
\text { change control process } \\
\text { - HFE anchored in strong } \\
\text { safety culture in nuclear } \\
\text { industry }\end{array}$ & $\begin{array}{l}\text { - Short time spans for } \\
\text { finding solutions - HFE } \\
\text { is mostly retrofitting } \\
\text { - Little time for HFE } \\
\text { considerations before } \\
\text { technology ins } \\
\text { implemented } \\
\text { - C1 more able to suggest } \\
\text { long-term solutions, but } \\
\text { also solves short-term } \\
\text { ones }\end{array}$ & $\begin{array}{l}\text { LOCALLY: } \\
\text { - HFE organized under } \\
\text { Human Resources (HR), } \\
\text { with Safety and } \\
\text { Environmental } \\
\text { - HR manager reports on } \\
\text { ergonomics to upper- } \\
\text { level management } \\
\text { GLOBALLY: } \\
\text { - MC strives to stay de- } \\
\text { centralized regarding HFE }\end{array}$ \\
\hline
\end{tabular}

developments, and the fact that they are positioned within plant engineering provides a directness of contact with design issues. The majority of HFE-related activities at the plant concern the replacement of functional parts in the system for the purpose of retaining the original function, rather than making large-scale changes or designing new systems. Changes to control room interfaces are avoided as much as possible.

Company $\mathrm{B}$ handles all engineering changes in the framework of its change control process protocol. From a HFE perspective, involvement from the Human Factors resource (B1) is 'designed' into this procedure by having to sign off on all projects as a "standing stakeholder". However, B1 is able to prioritize his involvement by categorizing the change as needing extensive $H F$ involvement, moderate involvement or no involvement. Engineers are procedurally required to get HF approval (from B1 or B2) on their proposals.

The support from upper-level management is plentiful however, B1 and B2 both note that a small percentage of engineers in the organization want to avoid HF involvement. B1 explains that the nuclear power industry has a historically well-engrained tradition of HFE, largely thanks to a strong safety culture and years of focusing on effective and safe human-machine interaction (HMI). Because of the nuclear sector's well-established regard for regulation compliance, redundancy and extra precautions, larger-scale changes and ideas can be difficult to implement due to the amount of 
interlocking procedures. B3 states: "the reality is that we've got thousands and thousands of procedures, so when somebody comes up with a good idea (...) the work to actually implement that, and be procedurally compliant (...) and then to train everybody and to communicate everybody, all 4000 employees on site, all the 1500 contractors, 'by the way, this has changed'? (...) it does happen, but it's very complicated."

\section{Company C - Seeing Opportunities vs Quick Implementations}

According to $\mathrm{C} 3$ (the project engineer) and C2 (the plant manager), implementation times for new products are driven by Company C's marketing department and can occasionally be very short (weeks to days). This sometimes means that the existing lines in the plant determine how changes to the production facility are implemented, since physical space is an issue. C2 explains that "It's very hard to change our process form, because of the space."

C3 explains that because production is steadily ongoing and schedules are tight, implementations often happen during weekends, the only production down-time. This means that there is seldom time for HFE issues to be considered before new technology is released. For this reason, most HFE issues are handled as retrofitting issues. C3 adds that the majority of capital budget goes to keeping the plant running and replacing worn-out equipment.

C1 is considered part of the Health and Safety department, and is located at a different plant than the other employees but spends much time travelling between different sites and working on changes to technical solutions in the different plants. She describes her job as "seeing opportunities" for improving ergonomics in parallel with productivity, manpower and efficiency, and reported varying levels of understanding and support for this from managers at each individual plant. Among her upper-level management, $\mathrm{C} 1$ reports having a very supportive Senior Vice President.

\section{Company D - Local Autonomy and Higher-Level Support}

On a local level in Company D, HFE is organized under Human Resources, alongside Safety and Environmental. The reason for this, says D3, is that the ergonomists collaborate closely with the medical staff when injuries are reported. The human resources manager ultimately reports on ergonomics to upper-level management, in reactive terms (compensation claims and absenteeism) as well as proactive terms (current ergonomics items in engineering designs). However, within the frame of the product delivery process, the ergonomist (D2) is a team member with a sign-off role from the initial design stage, and participates in design meetings with external contractors to assess the ergonomics aspects of new designs.

On a higher level, D1 is organized under MC's director of Occupational Health and Safety, who in turn is organized under MC's Executive Vice President of Human Resources. $\mathrm{MC}$ has established an assigned team of global corporate ergonomists to develop and roll out framework programs for addressing and tracking ergonomics in projects. Most such initiatives target plants that do not have in-house ergonomists, making sure that plants are given training in working as an ergonomics committee. The committees are trained by MC's global ergonomists to track the status of ergonomics on a colour-coded scale. Plants organized under MC are evaluated on five categories - one of which contains a criterion that all jobs should be evaluated against an ergonomic design checklist.

Typically, manufacturing truck frames at the order of a customer normally involves a 24-month time frame from request to launch, although this may vary considerably. The philosophy of MC has been to stay de-centralized and to impose as little as possible of their culture on any of the other branches, so they tolerate a variety of ergonomics procedures and cultural differences between the companies as long as each company has a tool to measure improvements in ergonomics and can demonstrate risk reductions as 'before and after' results. D1 notes that the practice of requiring engineering managers to be leaders of local ergonomics committees - which was initially resisted has also become more accepted, and even praised. Still, notes D1, some "old-school" managers are still resistant.

\subsection{Outside Influences}

Here, the "Extra-company" and "Environmental" levels described by Kirwan [8] are elaborated upon. Relevant external influences such as legislation, governing bodies, competitors, regulators, socio-political forces, events and values on the company's approach to HFE are described (Table 4).

\section{Company $A$ - Influenced by Engineering and US Legislation}

According to A1, no legislation governs ergonomics in the province, but since there is strict Health and Safety regulation in place for Canadian/North American companies (through the Ministry of Health and the Occupational Health and Safety Act), addressing an ergonomics issue becomes mandatory if it is made into a Safety issue. Apart from this, other governing bodies that affect the procedures of Company A include OSHA (Occupational Safety and Health Administration) that regulates workplace safety in North America, and WSIB (Workplace Safety and Insurance Board), who enforce worker compensation claims and make sure that companies pay premiums to cover injury and rehabilitation costs.

A3 also mentions that regarding software tools and development aids, there is an awareness among competitors in the automotive industry of which car manufacturers have specialized in research and development and which ones are using which 3D modeling systems. A3 describes that within Company A, they use engineering templates which incorporate external guidelines and limits, for example from $S A E$ (the Society of Automotive Engineers).

\section{Company $B-A$ Variety of Regulators and Sector Organizations}

B2 reports that Company $\mathrm{B}$ is obligated to follow requirements requiring system safety redundancy by its regulator, the CNSC (Canadian Nuclear Safety Commission) which mandates certain levels of HFE input at all nuclear power plants (a corresponding role to that of B1 exists at all Canadian nuclear power companies). One such mandate is 
Table 4. Key Characteristics of Companies A, B, C and D at the Extra-Company and Environmental Levels

\begin{tabular}{|c|c|c|c|c|}
\hline Level & Company A - Automotive & Company B - Nuclear & Company C - Poultry & Company D - Auto Parts \\
\hline Extra-company level & $\begin{array}{l}\text { - Strict North American } \\
\text { health \& safety } \\
\text { legislation } \\
\text { - Ergonomics issues } \\
\text { become mandatory to } \\
\text { address if they are made } \\
\text { into Safety issues } \\
\text { - Governing bodies: } \\
\text { OSHA, WSIB } \\
\text { - Awareness of } \\
\text { competitiors' use of } \\
\text { simulation tools } \\
\text { - SAE (engineering } \\
\text { guidelines) }\end{array}$ & $\begin{array}{l}\text { - Required to follow } \\
\text { regulator's requirements } \\
\text { (CNSC) } \\
\text { - OPEX operational } \\
\text { database search is } \\
\text { mandatory } \\
\text { - Influential organizations: } \\
\text { COG, INPO, WANO }\end{array}$ & $\begin{array}{l}\text { - Canadian quotas for } \\
\text { number of birds per day } \\
\text { - Overtime laws for } \\
\text { factory workers } \\
\text { - Quality Assurance drives } \\
\text { ergonomics, influenced } \\
\text { by HACCP } \\
\text { - C1 aware of competitors' } \\
\text { technology }\end{array}$ & $\begin{array}{l}\text { - Follows North American } \\
\text { safety legislation: } \\
\text { requires P.Eng } \\
\text { assessment } \\
\text { - WSIB enforces worker } \\
\text { health and safety } \\
\text { - Canadian Standards } \\
\text { Association (safety } \\
\text { standards) } \\
\text { - Customer requirements } \\
\text { drive changes } \\
\text { - Competitive business } \\
\text { quoting }\end{array}$ \\
\hline
\end{tabular}

for the HF agent to search for information on operational experience in the OPEX (Operational Experience) database, in order to include experience and knowledge collected industry-wide into new projects and to avoid repeating mistakes. Other influential organizations for the nuclear power industry include COG (CANDU Owner's Group, a Canadian organization), INPO (Institute of Nuclear Power Operations, a US organization) and WANO (World Association of Nuclear Operators). The industry also has a strong knowledge community who informally consult each other across company boundaries.

The nuclear industry is impacted by public perceptions of previous historical events involving nuclear reactor disasters. Such events have reinforced the strong human factors, safety and redundancy culture and the heavy regulations that must be adhered to. B1 explains: "since Three Mile Island, since Chernobyl (...) both of those have significant Human Factors aspects associated with those incidents."

\section{Company C-Food Safety First}

Due to the nature of the poultry business - where orders for a shipment of meat usually need to be fulfilled by the next day - the plant tries to optimize delivery of meat products to all customers in terms of maximizing their yield output (i.e. how much of each bird is used). A constraining factor, according to $\mathrm{C} 2$, is the quota system in Canada which limits the number of birds that the plant can slaughter per day. C1 says that a lot of work with ergonomics in the food industry is driven by Quality Assurance and influenced by methods like HACCP (Hazard Analysis Critical Control Points) standards for food safety. $\mathrm{C} 1$ and $\mathrm{C} 2$ report that a large proportion of C1's work with suggesting new technical solutions in plants comes from her awareness of available manufacturing technology and what competitors are using. This is a major advantage for $\mathrm{C} 1$, who is able to refer to ergonomic benefits gained in other companies as a powerful persuasion argument.
In relation to worker well-being, $\mathrm{C} 2$ says that he as plant manager expects $\mathrm{C} 4$ as HSSE manager to manage day-to-day HS issues in response to her data (e.g. absenteeism, WSIB claims and repetitive strains) and that she will act on this in relation to the requirements of government agencies and the plant's local union. Apart from this, C2 says that the only legislation that the plant must adhere to is overtime laws for the factory workers.

At the time of the interview, Company $\mathrm{C}$ had recently had a large recall of fresh meat products, which had a negative impact on the company in public opinion; $\mathrm{C} 1$ explains that the recall dominated all of the company's attention resources at the expense of other concerns. She says that this has affected her ability to collaborate on ergonomics design guidelines with other stakeholders such as Quality Assurance and Engineering: "the recall takes all the resources in the entire organization. And you just can't interfere (...)"

\section{Company D - Safety, Standards and Avoiding Claims}

Company D follows North American safety legislation, says D3, which requires a certified Professional Engineer (P.Eng) to assess and address any injury risks for workers prior to any new equipment being used in facilities, in a procedure called a Pre-Health and Safety review. Aside from this, the WSIB reinforces proactive attention to health and safety risks, since not addressing them is associated with financial repercussions. Assurance premiums are expensive, says D3, and in the event of an accident the WSIB can "fine divisions or companies for not following safety guidelines". Another legislative body that influences Company D is the Canadian Standards Association (CSA), which signs off on safety standards regarding technical configurations like controls and electrical wiring.

D3 reports that requirements from customers (the car manufacturers) determine the focus of what is to be incorporated and improved (e.g. quality issues) and that all 
Table 5. Key Characteristics of Companies A, B, C and D at the Temporal Dimension Level

\begin{tabular}{|c|c|c|c|c|}
\hline Level & Company A - Automotive & Company B - Nuclear & Company C - Poultry & Company D - Auto Parts \\
\hline Temporal dimension & $\begin{array}{l}\text { - Consolidation and } \\
\text { integration phase } \\
\text { - HFE work integrated and } \\
\text { proceduralized into } \\
\text { engineering } \\
\text { - Accountable } \\
\text { stakeholders assigned to } \\
\text { HFE } \\
\text { - Technologically well- } \\
\text { equipped } \\
\text { - Ergonomics involvement } \\
\text { has been expressed as } \\
\text { cost savings }\end{array}$ & $\begin{array}{l}\text { - Consolidation and } \\
\text { integration phase } \\
\text { - Meticulously managed } \\
\text { (electronic) change } \\
\text { control process } \\
\text { - Very good upper-level } \\
\text { management support, } \\
\text { strong HF culture }\end{array}$ & $\begin{array}{l}\text { - Between Proving and } \\
\text { Integration and } \\
\text { expansion phases } \\
\text { - HFE not integrated into } \\
\text { workflows, needs to be } \\
\text { emphasized by HF } \\
\text { agents } \\
\text { - Retrofitting } \\
\text { - HFE considered more of } \\
\text { a Safety issue, i.e. } \\
\text { separate from } \\
\text { Engineering } \\
\text { - HFE linked to business } \\
\text { objectives by C1's } \\
\text { projects }\end{array}$ & $\begin{array}{l}\text { - Consolidation and } \\
\text { integration phase } \\
\text { - Company-wide scorecard } \\
\text { reporting system with } \\
\text { HFE element } \\
\text { - Requests for ergonomics } \\
\text { simulation support } \\
\text { increasing } \\
\text { - Cultural shift towards HF } \\
\text { awareness } \\
\text { - More proceduralized, } \\
\text { engineers need } \\
\text { ergonomist's sign-off }\end{array}$ \\
\hline
\end{tabular}

business quoting is done competitively against other parts manufacturers.

At the time of the interviews, a major economic recession had recently taken place and impacted many North American industries negatively. Especially the automotive and related sectors had been severely affected, and participants from Company D (D1 and D2) reported that several plants under $\mathrm{MC}$ had been closed down since the recession. In remaining plants, personnel were laid off at several levels, both in production and other functions. These events had turned focus in the industry towards economic savings, and in some cases this emphasized the attitude of some plants towards HFE: in some places where ergonomics was not integrated with business and company goals, HFE staff had been decimated, while their position was in fact strengthened in places that had integrated and acknowledged HFE as an engineering concern.

\subsection{Organizational Integration of HFE}

Lastly, the temporal dimension [8] illustrates how far along an HFE integration process each company has come, as well as how the HF agents' work relates to the system design life cycle (Table 5). This is illustrated with brief accounts of how the HFE functions in each company have developed over time. Kirwan [8] also suggests 'phases' that a company's HFE function may be in, depending on how well-established it is in the company (pp. 675-677): I) the 'Proving' phase, building justification for HFE, II) Initial integration and expansion, and III) Consolidation and integration 'end-games'.

\section{Company A - Digital Review Brings Stakeholders Together}

The conditions at Company A suggest that the company has reached the "Consolidation and integration" phase [8]. Company A's HFE work is integrated, documented and assigned to accountable stakeholders. The technological sophistication of visualization tools (3D models and human simulation) is high. This means that Company A is generally well-equipped, organizationally and in terms of tools, to maintain a proactive HFE approach. The digital review has become standard technology for launch team meetings, as a result of a successful pilot project. The timing of HFE input is thereby planned and proceduralized, and launch team ergonomists remain assigned to newly-launched products for two months after implementation, increasing the likelihood of preventing work-related musculo-skeletal disorders (MSDs).

A2 has also noticed a transition since he started working at Company A as an engineer: in the past, engineers in his role would only make sure that the part fit in the $3 \mathrm{D}$ modeling world, but not that an operator would be able to assemble the part. The engineers would simply build and bring a physical part into the plant and get the operators' response to it. A2 says that the digital review now makes the meeting members talk about how to put parts together sequentially and whether the assembly is in line with ergonomics best practices. The last five years' progress has been significant in terms of avoiding operator injury, medical costs and absenteeism, says A2.

\section{Company B - Strong Industrial HFE Tradition}

By way of its strong HFE integration and support, Company B is also in the "Consolidation and integration" phase [8]. Company B's emphasized focus on safety permeates the meticulously managed change control process. B3 says that from an engineering point of view, concern for HFE is embedded in all procedures, including peer reviews of changes. As B1 and B2 point out, the fact that the change control process protocol has gone from being paper-based to electronic has considerably facilitated HFE involvement. The electronic system with its alerts and electronic updates increases the accessibility of project tracking for all involved stakeholders, and aids the HF specialist in 'catching' issues.

From a historical point of view, the HFE function at Company B was initially only involved with control panel issues, but later expanded because other groups saw good results and became interested. Currently, projects stem from a variety of domains requesting HF input.

B2 describes one interesting historical development: an initiative in the 1980s to apply human factors to operational issues resulted in a split of the discipline into human factors and human performance in the nuclear power industry. She notes that this industrial focus on human operations sometimes has had an adverse effect, overshadowing design aspects. 


\section{Company C-Still Proving the Merits of HFE}

The evidence indicates that Company $\mathrm{C}$ is somewhere between the "Proving" and "Integration and expansion" phases [8], since the HF agents ( $\mathrm{C} 1$ and $\mathrm{C} 4)$ pursue HFE responsibilities that are not integrated into the workflows of engineering, management or process. They still need to devote efforts to bringing HFE matters to light in engineering contexts.

However, there are some differences in how far HFE has come on the company-wide and local levels. Since the strongest driver for rapid local changes to the workplace is the Marketing department, there is little chance of having HFE involvement before new systems are implemented, and Company $\mathrm{C}$ lacks an established process to continuously involve HFE support. Since HFE issues are considered a pure Health and Safety concern, this separates HFE from engineering in the minds of many stakeholders, says $\mathrm{C} 1$.

On a local level, projects are coordinated by $\mathrm{C} 3$ and most equipment is built externally and then retrofitted in the plant. $\mathrm{C} 3$ feels that ergonomics "should be involved from the beginning" in projects but concedes that this does not always happen. Often, C4 does not hear about some changes until they are already in the plant. She thinks one solution to this problem could be to increase the daily contact of Health and Safety and Engineering, improving the visibility of the work being done on both sides.

At the same time, in the projects driven by $\mathrm{C} 1$ at different plants, there is a component of proactive HFE implementation firmly linked with business objectives. C1 does this with strong support from upper-level management, but getting local buy-in for the projects is highly dependent on the awareness and acceptance of ergonomics among plant managers, which $\mathrm{C} 1$ feels is a question of education: “...I know of opportunities out there. But (...) [the plant manager] doesn't think that I'm capable of more than lift tables." However, $\mathrm{C} 1$ feels that she is not in a position to demand that all projects be run by her either, due to lack of time on her side.

Some cultural resistance towards HFE remains in the company, which both $\mathrm{C} 1$ and $\mathrm{C} 4$ attribute to a persistent "old-fashioned" organizational culture. On a positive note, C1 feels that the plants with whom she has collaborated successfully in the past are becoming more mindful and are independently seeking her input.

\section{Company D - Strong Yet De-Centralized Accountability}

The established groups and integrated HFE component in most engineering projects suggests that Company D (as part of MC) has reached the "Consolidation and integration" phase [8]. D1 reflects that years ago, HF agents ran into many problems when trying to improve ergonomics through the HR/Safety function because problems were often sent to the Engineering department, who had no ergonomics accountability. D3 describes it as Engineering tending to "run with the projects", implementing changes without input from other stakeholders. However, since 2007 this has been mitigated by better local involvement procedures and the company-wide colour-dot system of reporting plant metrics every quarter. One of the criteria categories requires all jobs to be evaluated against an ergonomics checklist. Another category is dedicated to proactive ergonomics, but D1 feels that this needs to be supported more extensively in the future. One step in that direction is that plants are offered human simulation support. Requests have increased during the last two years, which D1 feels is part of a cultural shift towards better ergonomics awareness. Also, says D3, procedures for plant process changes are more proceduralized now, with engineers being required to put forward requests which need an ergonomist's sign-off. D3 says that although the priorities of different stakeholders may collide with ergonomics, Safety remains the highest priority.

\section{DISCUSSION}

This study demonstrates that HF agents' ability to influence ergonomics (as it is facilitated and hindered by their respective contexts) may vary across industrial sectors, and also is useful for demonstrating the reasons why some HF agents" "success" strategies can be more or less applicable to other industrial settings.

In general, macroergonomic literature places heavy focus on change management, participative ergonomics and interventions, but less attention is paid to day-to-day handling of ergonomics issues in ongoing production. This comparison study contributes to literature by examining dayto-day HFE activities and procedural conditions, instead of following time-limited intervention cases, thereby illuminating different aspects from some of the previous literature's focus (such as the studies described in [9]).

Previous literature regarding the influence of the social context, i.e. the immediately surrounding 'collegial influence' on an HFE agent's work, has been mainly concerned with following single or multiple case studies of ergonomics interventions [11-13], focused on implementation outcomes of Participative Ergonomics (PE) initiatives $[14,15]$, or prescriptive [16]. It was noted in some multiple case study papers that comparisons would have been aided by some form of standardization across cases, e.g. [17] in [15]. This paper aims to contribute towards this end, by focusing on empirical evidence of current practices.

In a review of corporate ergonomics interventions, Hägg [9] proposed that although company-internal documentation released to the research community provided a "picture of the state of the art", it was problematic that almost all of them were success stories. Inasmuch as the current state-ofthe-art at the four case companies is the result of modern ideals and 'lessons learned' from past events, some aspects of HFE evolution over time are addressed (as far as was possible from the participants' independent accounts) by the "temporal dimensions" section guided by Kirwan's [8] framework.

The participants in this study were generally very knowledgeable about their industrial sector and were collectively able to provide some knowledge on recent and historical developments. Although some evidence suggests that deep sector knowledge was crucial for HF agents to implement HFE work successfully, this was not explicitly stated in all interviews. The individual participant's strengths and experiential background sometimes also matters to their success as HF agents. 
In line with the results, it is recommended that the education of HFE specialists should include an extensive component of corporate-cultural contexts that surround ergonomics and human factors, so that students do not believe it to be merely a technical discipline performed in an instrumental, 'generic' manner. Greater awareness of how socio-technical influences may shape the "ergonomics infrastructure" in a company can be enabled by encouraging and exposing HFE students to real-world mentorship, plant excursions and corporate apprentice positions. The experience of context, nuances and company politics are bound to vary between companies, and students should be made aware of the difference between classroom knowledge (which is generalizable) and site-specific knowledge, which is unique to a situation but transferable. For these reasons, exposure to more than one company is preferable. Also, students should be equipped with skills to identify such political influences, and it is the suggestion of the author that Kirwan's framework [8] may be a very useful tool for students to approach and reflect one or more company settings.

Many participants emphasized that linking HFE to business and economical objectives was a crucial factor for achieving broad company support. Hägg [9] also noted that a participative approach and ergonomics expertise were crucial factors for successful interventions, while a lack of linkage between ergonomics and company core values could often hinder interventions. This seems to be true also for the companies studied in this paper.

The author therefore proposes that the influence of industrial sector expertise should be studied more explicitly.

\section{SUMMARY OF COMPARISONS}

Company A appeared to be fairly typical of the North American automotive industry, with a top-down hierarchical structure, high acceptance for ergonomics, good integration of ergonomics into engineering processes and a high degree of contact between HF agents and other development functions, as well as good tool/method/procedural support. Company A has strong managerial support for ergonomics, links HFE issues to business objectives and involves operators in launch projects.

Company B exemplifies the nuclear industry's rigorous safety culture. The organizational structure is top-down and the HF agent(s) have empowerment (in terms of being a sign-off role). The HFE-related engineering activities in Company B are geared mainly at supporting/maintaining production processes, while retaining the same functionality. There is good procedural infrastructure in place for proactive involvement of the HF agent. Some of the main barriers to implementing large-scale ideas come from the heavy degree of procedural compliance, which complicates the process of getting new solutions approved.

Company $\mathrm{C}$ appeared to have the least amount of integrated HFE of the studied companies. The participants explain that priorities like production output and quick implementation during plant down-time drive a tendency to implement first and fix issues later. Implementation of improvements is also subject to plant space constraints. The HFE work on a local level is mostly on a day-to-day reactive basis, with ergonomics being considered part of Health and
Safety, while on a higher level the HFE work being done by $\mathrm{C} 1$ is a result of good high-level management support and $\mathrm{C} 1$ 's personal experience and aspirations.

Company D drives a flexible and adaptive ergonomics program from the top down, which lets individual plants determine their own best practices for handling HFE issues, as long as the results of HFE interventions can be tracked electronically across all the companies under MC. HFE is integrated locally at Company D, through an involvement procedure for the ergonomist (D2) to be part of the launch team for new products. The ergonomist is able to give proactive input and has a sign-off role.

On the technical interface level, Company $\mathrm{A}$ is characterized by teamwork, ergonomist involvement in new products and recurring digital visualization meetings. This last characteristic is present also in Companies $\mathrm{B}$ and $\mathrm{D}$, who also both use electronically supported processes for tracking engineering changes and scorecard metrics respectively. While Company $\mathrm{B}$ is characterized by having the HF personnel in a sign-off role, Company D concentrates on centrally providing support and ergonomics training to the plants but letting them retain their autonomy if they have a local ergonomist. Company $\mathrm{C}$ is set apart from the others in a number of ways - HFE is not electronically supported or proceduralized, and any HFE-related solutions related to production/business objectives are carried out at the initiative of the global ergonomics manager.

At the project level, the differences in project cycle length and type vary between the studied companies; products from Company A take six years from concept to production launch, and at Company $\mathrm{D}$ the corresponding time is 24 months. However, Company B and C are similar in this regard, in the sense that production is mostly ongoing from day-to-day; at Company $\mathrm{B}$ the production of power involves mostly maintenance and at Company $\mathrm{C}$ the basic product remains mostly the same. However, Company $\mathrm{C}$ is characterized by marketing-driven rapid implementations to the production floor, making it difficult to plan for HFE involvement.

At the company level the HF agents at each company are positioned differently in their respective organization. Ergonomists at Company A are a free-floating function but assigned to projects, while at Companies B, C and D their role is more of a screening and approval function. Close collaboration or association of HFE with Safety is explicit in Companies A, B and C, while Company D places HFE with Human Resources (where it is placed alongside Safety). Input toward changes is given by all $\mathrm{HF}$ agents at some point, however the procedures at Companies A, B and D make the input more proceduralized than at Company $\mathrm{C}$, where HFE involvement is more ad-hoc. This ties in with the personnel level; $\mathrm{HF}$ agents are rarely at a higher position in a company hierarchy, however the proceduralized sign-off position at Companies A, B and D allows the HF agents at least an influence of approval and advice. At Company C, the amount of HFE input is at the discretion of $\mathrm{C} 1$ and $\mathrm{C} 4$. At all of the companies, the HF agents experienced mostly good HFE support from higher-level management, although at companies $\mathrm{C}$ and $\mathrm{D}$ (who both had global and local HF agents) there were varying levels of acceptance from plant managers. 
At the extra-company level, Company B stands out as being the most extensively regulated by several nuclear power organizations. The upside of this is that access to vast amounts of HFE and operational experience is available through these organizations. Aside from this, Companies A and D follow North American Safety legislation and try to avoid WSIB fines. Some engineering organizations influence the two; SAE is mentioned for Company $\mathrm{A}$, and the Canadian Standards Association for Company D.

It is perhaps chiefly Companies $\mathrm{B}$ and $\mathrm{C}$ that are specifically targeted at the environmental level; several historical nuclear incidents have served to place the nuclear industry under a watchful eye from the public and increase demands on safety and redundancy, while the negative public impact of a meat product recall from Company $\mathrm{C}$ exhausted some in-company resources that could otherwise have gone to HFE. At the time that the study was carried out, a recession had recently taken place, which had negatively impacted the automotive and related industries. Thus, both Companies A and D had recently been affected, with closures of plants and decimation of personnel.

Finally, the degree of HFE integration, the temporal dimension, seemed similar for the three proceduralized, technologically supported companies A, B and D (which were all in the consolidation and integration phase [8]), while Company $\mathrm{C}$ (in between the Proving and Integration and expansion phases) still appeared to be placing efforts on proving the merits of HFE, trying to make other stakeholders see it not as purely a safety issue but as a way to improve business goals. HFE was not as integrated into other workflows at Company $\mathrm{C}$, as at the other companies.

In summary, certain factors described by the participants contribute to what might be called a company "infrastructure" that significantly enables and reinforces HFE approaches that are either proactive or reactive. These factors are suggested in Table 6, with companies exemplifying these points in parentheses:

\section{METHODOLOGICAL CONSIDERATIONS / STUDY LIMITATIONS}

A limitation of the study is that it is entirely based on interviews with a limited number of people, and although the veracity and internal validity of the interviews is secured per se by audio recording and transcription, they capture only the perceptions of participants and the company descriptions are entirely based on their reports (which sometimes did not match up due to differences between participants in site locations and perceptions of what was asked for). Also, there could only be limited verbatim reporting of the participants' accounts due to the extensive coverage of the comparison framework [8].

The selection of interviewees was purposeful, rather than random [18], meaning that participants were selected because they were presumed to be specifically able to inform the study. This motivates why companies were recruited on the basis of having a dedicated HF agent - this ensured a structural baseline across the studied companies, and also increased the chances that the companies would be able to provide relevant information during the limited time period that the recruitment study took place. To cover collaboration aspects, additional interviewees were recruited within each company through the HF agent's contact network. It is reasonable to suspect that the 'snowball'- recruited participants had a good working relationship with the HF agent, and thus it must be kept in mind that this study may be chiefly informed by participants with an accepting attitude towards HFE work, and therefore has little possibility of independently revealing any antagonistic relationships (if such existed).

Interviews with the first participants in each cluster tended to be longer, since some time was spent during initial interviews providing the interviewer with background information about the company. As the interviewer learned more about the organizational structure and procedures at each company, less time was spent on these issues with participants interviewed later on, explaining the difference in interview length (30 minutes to approx. one hour).

The stratified soft-systems framework [8] provides a helpful structure to the comparison, although at some levels there were manifestations of HFE that "blended" between adjacent levels. For this reason, several levels were reported together. This stratification also affects the "storytelling" order, which arguably is significant in order for the reader to understand the conditions at the four case companies.

\section{CONCLUSIONS}

- The ability of HFE agents to have any impact with their work is affected by company "infrastructure" in the form of technical communication support,

Table 6. Conditions that Reinforce Proactive or Reactive HFE Approache

\begin{tabular}{|c|c|}
\hline $\begin{array}{l}\text { - Proceduralized inclusion of HF agent in new projects (A, B, } \\
\text { D) } \\
\text { - } \\
\text { - } \\
\text { - } \\
\text { - Slanned continuous involvement (A, D) } \\
\text { and experience databases (A, B, D) } \\
\text { - } \\
\text { - } \\
\text { Pign-off mandates (A, B, D) } \\
\text { (A, B, D) } \\
\text { - Scorecard metrics concerning ergonomics evaluation of } \\
\text { designs (A, D) }\end{array}$ & $\begin{array}{ll}\text { - } & \text { Associating HFE with HS, HR or a medical company function (C, D) } \\
\text { - } & \text { Focus on injury statistics (C, D) } \\
\text { - } & \text { Lack of consistent involvement processes for HF agents (C) } \\
\text { - } & \text { Fast implementation processes (C) } \\
\text { - } & \text { Short delivery times (C) }\end{array}$ \\
\hline
\end{tabular}


meeting forums, project setups, organizational positioning, ranking and stratification/integration of HF agents.

- In the studied companies with good "HFE infrastructure", a HF agent is involved early, has a sign-off role in order for the process to be approved, and contact with other product- and production-related disciplines is facilitated by structured, recurring meetings and technological communication tools.

- The HFE infrastructure is influenced by outside influences such as regulatory requirements, professional organizations, standards, claims management bodies and contemporary socio-political ideals, expectations and events.

- Integration of HFE into the organization's engineering procedures, linkage between HFE and business goals, and upper-management level support are three good indicators that a company is able to work proactively with HFE.

- In the studied companies where HF agents spend efforts on establishing the legitimacy of HFE improvements, the overall HFE approach tends to be reactive and focused on reducing injury statistics.
- HFE educations should include a component of exposure to real companies in order to introduce HF students to stratified influences on HFE work on different levels.

- $\quad$ HF agents and other professionals may be well served by using Kirwan's [8] stratified soft systems model as a structured guide to learning about an organization's HFE infrastructure.

\section{ACKNOWLEDGEMENTS}

The author would like to thank the participants of this study for helping in the company-internal recruitment process, and Dr. W. Patrick Neumann of the Human Factors Engineering $L a b$ at Ryerson University for aiding the recruitment and analysis at various stages and providing constructive feedback on an earlier version of this paper. This study was made possible by generous financial support from The Lars Hierta Memorial Foundation, Stiftelsen fond till minne av ömsesidiga Olycksfallsförsäkringsbolaget Land och Sjö, and Chalmersska Forskningsfonden which allowed the author to carry out field research in Ontario, Canada.

\section{CONFLICT OF INTEREST}

None Declared.

\section{APPENDIX A}

This paper's results are reported following a structure described by [8]. This soft-systems framework is specifically targeted at enhancing Human Factors/Ergonomics into organizations, and details the characteristics of seven different stratified organizational levels, starting with factors close to the HF agent(s) and gradually expanding outwards toward the organization's environment (Fig. 1).

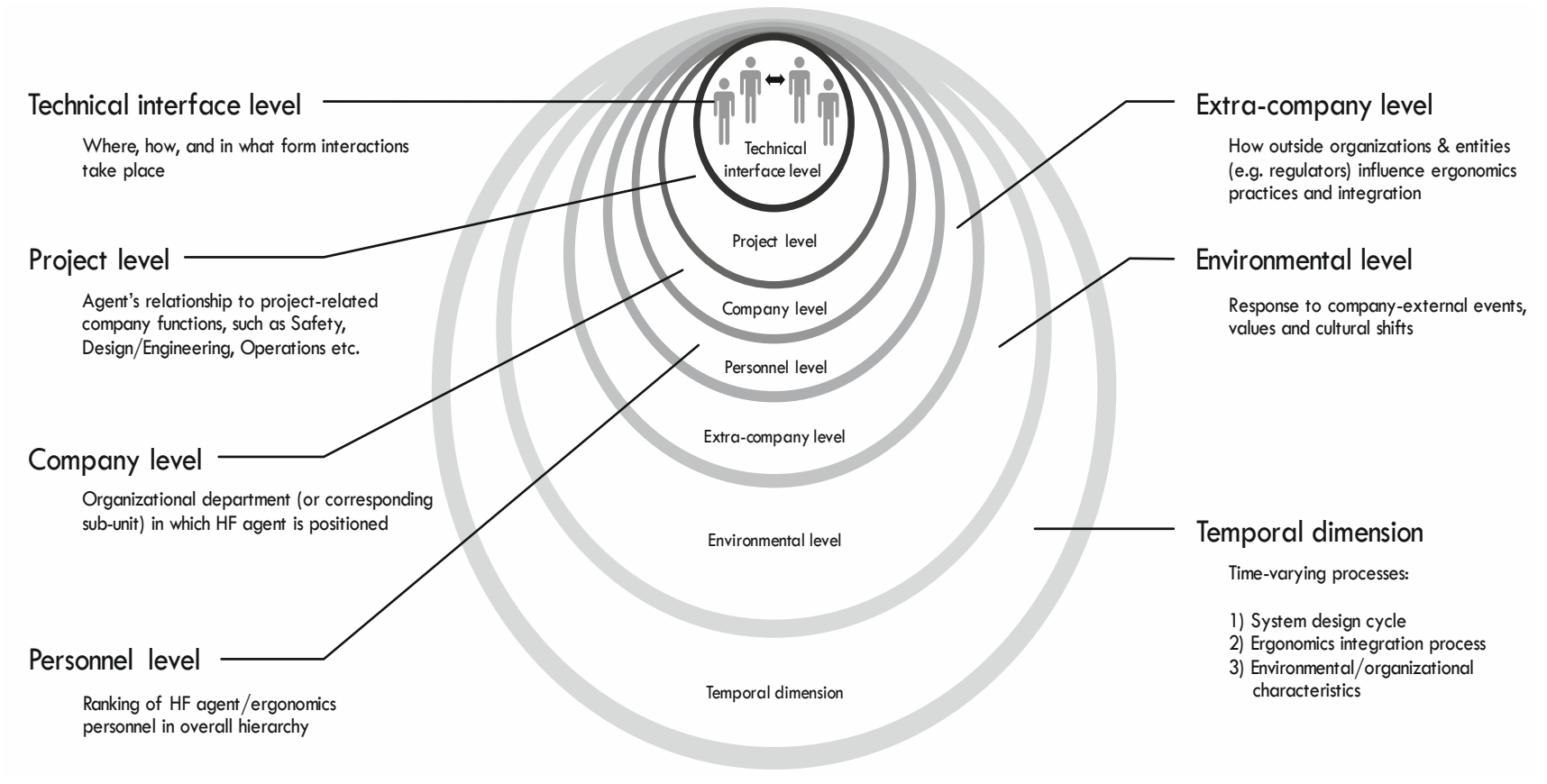

Fig. (1). Kirwan's stratified soft systems framework for increased HFE integration - adapted from Kirwan ([8], p. 666 -678).

This appendix provides an overview of these levels and their characteristics and manifestations, which were sought after in the results of the interview study. Table 7 summarizes briefly the conceptual description and manifested elements at each level. 
Table 7. The Seven Levels of Kirwan's Stratified Soft Systems Framework - Adapted from Kirwan ([8], pp. 666 -678)

\begin{tabular}{|c|c|c|}
\hline Level & Conceptual Description & Manifested Elements \\
\hline Technical interface level & $\begin{array}{l}\text { Where, how, and in what form interactions } \\
\text { take place }\end{array}$ & Meetings, reports, other media, presentations, papers, press releases \\
\hline Project level & $\begin{array}{l}\text { The HF agent's relationship to project-related } \\
\text { company functions, typically with Safety, } \\
\text { Design/Engineering and Operations functions }\end{array}$ & $\begin{array}{l}\text { Stakeholder (colleague) interfacing, the nature of the assignment(s), project } \\
\text { duration, the HF agent's status as a team member or solitary actor, the } \\
\text { possibility of using new HFE approaches, potential to show business } \\
\text { potential of HFE }\end{array}$ \\
\hline Company level & $\begin{array}{l}\text { The organizational department (or } \\
\text { corresponding sub-unit) in which HFE is } \\
\text { positioned }\end{array}$ & $\begin{array}{l}\text { (Depending on the organizational position): Access to end users, short- or } \\
\text { long-term solutions, ergonomic design compliance, closeness/distance to } \\
\text { operations, justification for HFE depending on safety or other concerns, } \\
\text { time spans for finding solutions }\end{array}$ \\
\hline Personnel level & $\begin{array}{l}\text { Ranking of the HF personnel in the overall } \\
\text { hierarchy }\end{array}$ & $\begin{array}{l}\text { Hierarchical placement of HF agent, closeness to 'the top', understanding } \\
\text { of business/product/ process aspects, level of understanding and support } \\
\text { from senior management, ability to raise HFE issues 'high up', alignment } \\
\text { of HFE matters to company's needs and goals }\end{array}$ \\
\hline Extra-company level & $\begin{array}{l}\text { Influence on HFE practice and integration } \\
\text { from organizations and entities outside the } \\
\text { company }\end{array}$ & $\begin{array}{l}\text { Regulators, governing bodies, national/international standards, } \\
\text { competitors, industrial forums, academic organizations, operator-based } \\
\text { organizations }\end{array}$ \\
\hline Environmental level & $\begin{array}{l}\text { The company HFE function's response to } \\
\text { company-external events, values and cultural } \\
\text { shifts }\end{array}$ & $\begin{array}{l}\text { Government policies, take-overs (or similar corporate change events), } \\
\text { privatization, responses to incidents and accidents, public perception of } \\
\text { HFE issues }\end{array}$ \\
\hline Temporal dimension & $\begin{array}{l}\text { How far the company has come in time- } \\
\text { varying processes: 1) the system design life } \\
\text { cycle, } 2 \text { ) the HFE integration process, and } 3 \text { ) } \\
\text { environmental / organizational temporal } \\
\text { characteristics }\end{array}$ & $\begin{array}{l}\text { How long the HFE presence has existed at the company and in what } \\
\text { organizational form (e.g. person, committee, unit, department), how long it } \\
\text { has taken to develop and integrate into the company's organization and } \\
\text { 'business mission' }\end{array}$ \\
\hline
\end{tabular}

\section{REFERENCES}

[1] Checkland PB. Soft systems methodology: a thirty year retrospective. Syst Res 2000; 17: S11-S58.

[2] Westgaard RH. Work-related musculoskeletal complaints: Some ergonomics challenges upon the start of a new century. Appl Ergon 2000; 31(6): 569-80.

[3] Costa-Black KM, Durand M, Imbeau D, Baril R, Loisel P. Interdisciplinary team discussion on work environment issues related to low back disability: a multiple case study. Work 2007; 28(3): 249-65.

[4] Theberge N, Neumann WP. Doing 'organizational work': Expanding the conception of professional practice in ergonomics. Appl Ergon 2010; 42(1): 76-84.

[5] Broberg O, Hermund I. The OHS consultant as a 'political reflective navigator' in technological change processes. Int J Indust Ergon 2004; 33: 315-26.

[6] Hendrick HW. Determining the cost-benefits of ergonomics projects and factors that lead to their success. Appl Ergon 2003; 34(5): 419-27.

[7] Skepper N, Straker L, Pollock C. A case study of the use of ergonomics information in a heavy engineering design process. Int J Indust Ergon 2000; 26(3): 425-35.

[8] Kirwan B. Soft systems, hard lessons. Appl Ergon 2000; 31(6): 663-78.

[9] Hägg GM. Corporate initiatives in ergonomics - an introduction. Appl Ergon 2003; 34(1): 3-15.

[10] QSR NVIVO. NVIVO 8 - Getting Started. Users manual. QSR International Pty Ltd. 2008.
[11] Waterson P, Kolose SL. Exploring the social and organisational aspects of human factors integration: A framework and case study. Saf Sci 2010; 48(4): 482-90.

[12] Wulff IA, Westgaard RH, Rasmussen B. Ergonomic criteria in largescale engineering design - I: Management by documentation only? formal organization $v s$ designers' perceptions. Appl Ergon 1999; 30(3): 191-205.

[13] Wulff IA, Westgaard RH, Rasmussen B. Ergonomic criteria in largescale engineering design - II: Evaluating and applying requirements in the real world of design. Appl Ergon 1999; 30(3): 207-21.

[14] Broberg O, Andersen V, Seim R. Participatory ergonomics in design processes: The role of boundary objects. Appl Ergon 2011; 42(3): 46472.

[15] Cole DC, Theberge N, Dixon SM et al. Reflecting on a program of participatory ergonomics interventions: a multiple case study. Work 2009; 34(2): 161-78.

[16] Perrow C. The organizational context of human factors engineering Admin Sci Q 1983; 28(4): 521-41.

[17] St-Vincent M, Toulouse G, Bellemare M. Démarches d'ergonomie participative pour réduire les risques de troubles musculo- squelettiques: Bilan et réflexions. Pistes 2011; (2): 1-38. Available at: www.unites. uqam.ca/pis tes/v2n1/articles/v2n1a5.htm [Accessed 17/05/2011].

[18] Maxwell JA. Qualitative research design: An interactive approach. $2^{\text {nd }}$ ed. Thousand Oaks, CA: SAGE Publications 2005.

(c) Cecilia Berlin; Licensee Bentham Open.

This is an open access article licensed under the terms of the Creative Commons Attribution Non-Commercial License (http: //creativecommons.org/licenses/ by-nc/3.0/) which permits unrestricted, non-commercial use, distribution and reproduction in any medium, provided the work is properly cited. 